\title{
Enzymatic Preparation and Structure-activity Relationship of Sesaminol
}

\author{
Jinhong Gao', Ruidan Wang ${ }^{1}$, Xin Lu', Cong Jia', Qiang Sun², Jinian Huang ${ }^{1,2 *}$, \\ Songli Wei ${ }^{2}$, and Lin Ma ${ }^{1}$ \\ ${ }^{1}$ Research Centre for Agricultural and Sideline Products Processing, Henan Academy of Agricultural Sciences, 116 Park Road, Zhengzhou \\ 450002, Henan province, P.R.CHINA \\ ${ }^{2}$ Institute of Agricultural and Sideline Products Processing, Henan Academy of Agricultural Sciences, 116 Park Road, Zhengzhou 450002, \\ Henan province, P.R.CHINA
}

\begin{abstract}
As a valuable natural antioxidant, sesaminol can be used in food and medicine industries, but it is trace in sesame seeds and oil, and it is feasible to prepare sesaminol from sesaminol triglucoside (STG) which is abundant in defatted sesame cake. Therefore, in order to establish an effective enzymatic preparation method and elucidate the antioxidant structure-activity relationship of sesaminol, a suitable glycosidase for preparing sesaminol from STG were screened, enzymatic hydrolysis was optimized by single-factor test and response surface methodology, and finally, the structure-activity relationship of sesaminol was illustrated by comparative molecular field analysis (CoMFA). These results suggested that $\beta$ galactosidase was the optimal glycosidase for enzymatic hydrolysis of STG to prepare sesaminol. Under the optimal conditions of a reaction temperature of $50^{\circ} \mathrm{C}$, reaction time of $4.0 \mathrm{~h}, \mathrm{pH}$ of 5.5 , substrate concentration of $1.0 \mathrm{mg} / \mathrm{mL}$, and enzyme dosage of $20 \mathrm{mg} / \mathrm{mL}$, the conversion rate of sesaminol was $\mathbf{9 8 . 8 8} \pm 0.67 \%$. Sesaminol displayed excellent antioxidant ability in 2,2-diphenyl-1-picrylhydrazyl (DPPH, $\left.\mathrm{IC}_{50}=0.0011 \mathrm{mg} / \mathrm{mL}\right), 2,2^{\prime}$-azinobis-(3-ethyl-benzothiazoline-6-sulfonate) $\left(\mathrm{ABTS}, \mathrm{IC}_{50}=0.0021 \mathrm{mg} / \mathrm{mL}\right)$ radical scavenging activities and Ferric reducing antioxidant power (FRAP, 103.2998 mol/g) compared to other sesaminol derivatives. According to $-\log \left(\mathrm{IC}_{50}\right.$ of DPPH) and $-\log \left(\mathrm{IC}_{50}\right.$ of ABTS), CoMFA models were successfully established based on $\mathrm{Q}_{2}>0.5\left(\mathrm{Q}_{\mathrm{DPPH}}{ }^{2}=0.558, \mathrm{Q}_{\mathrm{ABTS}}{ }^{2}=0.534\right)$. The active site of sesaminol tended to be located on the hydroxyl group of the benzene ring ( $R_{1}$ position). A positive correlation between the bulky and positively charged groups at the $1 \mathrm{H}, 3 \mathrm{H}$-furo $[3,4-\mathrm{c}]$ furan group, the small, negatively charged groups at the $\mathbf{R}_{1}$ position and the antioxidant activity of sesaminol. This study provides an effective method to prepare sesaminol, reveals the structure-activity relationship of sesaminol and provides theoretical basis to design the novel compound.
\end{abstract}

Key words: sesaminol triglycoside, sesaminol, enzymatic hydrolysis, antioxidant activity, structure-activity relationship

\section{Introduction}

Oxidative stress occurs when the amount of free radicals such as superoxide, hydrogen peroxide and nitric oxide exceeds the ability of cells to remove them through antioxidant defence mechanisms ${ }^{1)}$. It is well known that oxidative stress can accelerate ageing and lead to the occurrence and development of inflammation, hepatocarcinogenesis and degenerative diseases in elderly individuals ${ }^{2-4}$. Some antioxidant additives may be critical for the alleviation of stress-related diseases ${ }^{5,6)}$. Although synthetic antioxidants such as TBHQ and BHA have been commonly added to food, there is growing anxiety about synthetic antioxidants due to the risk of carcinogenic and liver damage ${ }^{7)}$. Recent studies have focused on developing and utilizing antioxidants from edible natural sources ${ }^{8)}$.

Sesame (Sesamum indicum L) is an important oilseed worldwide. It is one of the most popular health oilseeds due to its lignan derivatives, such as sesamin, sesamolin, sesaminol and their glycosides ${ }^{9}$. These compounds benefit human health, exhibiting antioxidant, anti-ageing, and antiinflammatory properties, among others ${ }^{10-12)}$. Among the lignans of sesame, sesaminol has shown more potent antioxidant activity in vitro experimental system than $\alpha$-tocopherol and $\mathrm{BHT}^{13)}$. In addition, sesaminol can \footnotetext{
Agricultural Sciences, 116 Park Road, Zhengzhou 450002, Henan province, P.R.CHINA

E-mail: jinianhuang71@ gmail.com ORCID ID: Jinhong Gao (https://orcid.org/0000-0002-8536-6807) Accepted May 15, 2021 (received for review March 29, 2021)

Journal of Oleo Science ISSN 1345-8957 print / ISSN 1347-3352 online

http://www.jstage.jst.go.jp/browse/jos/ http://mc.manusriptcentral.com/jjocs
}

*Correspondence to: Jinian Huang, Research Centre of Agricultural and Sideline Products Processing, Henan Academy of

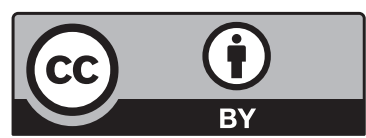


improve the usability of tocopherols in organisms and inhibit oxidative modification in $\mathrm{DNA}^{14)}$. Therefore, sesaminol is considered one of the most valuable natural antioxidants. However, few studies have been carried out on the antioxidant activity of sesaminol compared with that of other natural antioxidants, such as flavonoids and polyphenols ${ }^{15,16)}$. Moreover, little attention has been given to relevant studies of sesaminol and its structure-activity relationship. As a naturally occurring trace compound, the content of sesaminol is low in sesame seeds and oil and is difficult to synthesize, which limits relevant study and application $^{13)}$.

Some researchers separated sesaminol from roasted sesame oil or refined sesame oil ${ }^{17,18)}$, sesaminol content was no more than $2 \mathrm{mg} / 100 \mathrm{~g}$ and $10 \mathrm{mg} / 100 \mathrm{~g}$ in sesame seed and sesame oil respectively. This method was unsatisfactory due to low yield and reduction in the nutrition and edible values of sesame oil. Other researchers have prepared sesaminol from sesamolin by chemical reactions in organic medium ${ }^{19)}$. However, residues of organic solvents are a risk in the application of the food and pharmaceutical industry. Some attempts have been made to prepare sesaminol from water-soluble sesaminol triglycoside(STG) by enzymes. STG can be effectively extracted from defatted cake, which is a rich byproduct of sesame oil industries. However, low yield and long reaction time limit the preparation of sesaminol by enzymes. Peng $e t a l .{ }^{20)}$ reported that the yield of sesaminol prepared by enzymatic hydrolysis of STG for $24 \mathrm{~h}$ was only $48.9 \%$. Therefore, it is urgent to solve the problem of the time-consuming and low conversion rate of sesaminol by optimizing tool enzyme and hydrolysis conditions. Moreover, previous research has not considered the degradation rule of STG. STG transforms into either sesaminol directly or sesaminol diglycoside (SDG) or sesaminol monoglycoside (SMG) indirectly during enzymatic hydrolysis, and SDG or SMG becomes sesaminol via further hydrolysis.

In this study, a suitable enzyme was selected from common glycosidases, and then its enzymatic conditions for the preparation of sesaminol from STG were optimized by a single-factor experimental design and the response surface method (RSM). The transformation rules of SMG and SDG were analysed. Moreover, comparative molecular field analysis (CoMFA) was built to clarify the structure-activity relationship of sesaminol.

\section{Experimental Procedures}

\subsection{Materials}

Sesame seeds were obtained from a local supermarket. STG, SDG, SMG and sesaminol were prepared in laboratory. Sesamin, sesamolin, sesamol, asarinin, paulownin, cellulase $(0.7 \mathrm{U} / \mathrm{mg}), \beta$-glucanase $(2.0 \mathrm{U} / \mathrm{mg}), \beta$-glucosidase (2.0 U/ mg), $\beta$-galactosidase (8.0 U/mg), 2,2'-azinobis-(3-ethylbenzothiazoline-6-sulfonate) (ABTS), 2,2-diphenyl-1-picrylhydrazyl (DPPH) and methanol of HPLC grade were purchased from Sigma-Aldrich (St. Louis, MO, USA). Methylophiopogonanone A and methylophiopogonone A were obtained from Chengdu Prifa Technology Co., Ltd. (Chengdu, China). Without additional statements, all other chemicals were purchased from Sinochem(Shanghai, China).

\subsection{Preparation of STG, SDG, SMG and sesaminol}

STG was isolated from defatted sesame cake according to Zhu et al.'s method ${ }^{21)}$ with some modifications. Defatted sesame cake was extracted with $75 \%$ ethanol $(\mathrm{v} / \mathrm{v})$ at a ratio of $1: 8(\mathrm{w} / \mathrm{v})$ and stirred at $20^{\circ} \mathrm{C}$ for $8 \mathrm{~h} 3$ times. The supernatant was merged, concentrated and lyophilized to obtain a crude extract rich in STG. 2 g crude extract was dissolved in distilled water $(10 \mathrm{~mL})$, and then the solution was added to an open column $(5.0 \times 50 \mathrm{~cm})$ package with polyamide(100-200 mesh). Distilled water as the mobile phase eluted the column and flowing at $1.0 \mathrm{~mL} / \mathrm{min}$. The eluate was collected with an automatic DBS 100 collector (Huxi Analysis Instrument Factory Co., Ltd., Shanghai, China) in $10 \mathrm{~mL}$ portions and tested with HPLC and LC-ESI/MS. According to the determined results, the fraction was collected and freeze-dried to achieve purified STG.

The preparation methods of SDG, SMG and sesaminol were developed according to the results in this study. SDG and SMG were prepared from STG by $\beta$-galactosidase, and their enzymatic hydrolysis conditions were the same except for the $\mathrm{pH}$. Two amounts of $50 \mathrm{mg}$ STG were dissolved in a $25 \mathrm{~mL}$ of $0.05 \mathrm{~mol} / \mathrm{L}$ citrate buffers at a $\mathrm{pH}$ of 3.0 and a $0.05 \mathrm{~mol} / \mathrm{L}$ phosphoric acid buffer at a $\mathrm{pH}$ of 7.0. SDG and SMG were prepared by enzymatic hydrolysis under the same reaction conditions of $50^{\circ} \mathrm{C}$, an enzyme dosage of 20 $\mathrm{mg} / \mathrm{mL}$ and a reaction time of $3.0 \mathrm{~h}$, and then the reaction solutions were boiled for $5 \mathrm{~min}$ and centrifuged at 12000 rpm for $15 \mathrm{~min}$. The supernatants were collected and loaded onto a Sephadex LH-20 column $(2.0 \times 50 \mathrm{~cm})$. Distilled water was used as the eluent, and the flow rate was $1.0 \mathrm{~mL} / \mathrm{min}$. The eluate was assembled in $10 \mathrm{~mL}$ increments with an automatic collector, and the fractions containing SDG/SMG were tested, gathered and lyophilized.

Sesaminol was also prepared from STG by $\beta$-galactosidase, and the enzymatic hydrolysis conditions were the same as the enzymatic hydrolysis conditions of SDG/SMG except that the $\mathrm{pH}$ was 5.5. After the reaction was completed, the reaction mixture was centrifuged, 50 $\mathrm{mL}$ ultrapure water was added to the precipitate, and then the mixture was shaken for 2 min and centrifuged again at $12000 \mathrm{rpm}$ for $15 \mathrm{~min}$. Then, $50 \mathrm{~mL}$ ethanol was added to the precipitate, the mixture solution was shaken for $2 \mathrm{~min}$ and separated by centrifugation, and the supernatant was 
collected. This step was repeated 3 times. All the supernatants were combined and enriched by rotary evaporation. After vacuum freeze-drying for $36 \mathrm{~h}$, sesaminol was tested and collected.

\subsection{Determination and identification of STG, SDG, SMG and sesaminol}

The analysis of STG, SDG, SMG and sesaminol was performed on a Thermo Fisher Scientific Ultimate 3000 series HPLC system (Thermo Fisher Scientific, Waltham, MA, USA), a UV detector and an Agilent 5 TC-C18(2) (250 mm $\times 4.6 \mathrm{~mm}, 5 \mu \mathrm{m}$ ) column (Agilent, CA, USA). The temperature of column oven is set at $30^{\circ} \mathrm{C}$. The mobile phase are methanol (solvent A) and water (solvent B), the gradient system is as follows: $0-10 \mathrm{~min}(1 \mathrm{~mL} / \mathrm{min}, 40 \% \mathrm{~A}) ; 15-30$ $\min (0.8 \mathrm{~mL} / \mathrm{min}, 40 \% \mathrm{~A}) ; 40-50 \mathrm{~min}(1 \mathrm{~mL} / \mathrm{min}, 80 \% \mathrm{~A})$, $55 \mathrm{~min}(1 \mathrm{~mL} / \mathrm{min}, 80 \% \mathrm{~A})$ and $60 \mathrm{~min}(1 \mathrm{~mL} / \mathrm{min}, 40 \% \mathrm{~A})$. The absorbance was monitored at $287 \mathrm{~nm}$ for STG, SDG and SMG and $293 \mathrm{~nm}$ for sesaminol. The injection volume was $5 \mu \mathrm{L}$.

The molecular weights of STG, SDG, SMG and sesaminol were identified by LC-ESI/MS. LC-ESI/MS analysis was carried out by using an Ultimate 3000-Q Exactive-Orbitrap (Thermo, MA, USA) and a positive model.

\subsection{Selection of optimum enzyme for preparation of sesa- minol and qualitative analysis of enzymatic hydrolysis products}

According to related literature ${ }^{22,23)}$, cellulase, $\beta$-glucanase, $\beta$-glucosidase and $\beta$-galactosidase were tested in the experiment, and their optimum conditions are shown in Table 1. $10 \mathrm{mg}$ STG was mixed with $10 \mathrm{~mL}$ buffer solution. Glycosidase was added to the reaction solution at the same amount of enzyme activity. The reaction solution was shaken in a water bath for $8.0 \mathrm{~h}$ at the optimal temperature. The sample was boiled for 5 min followed by centrifugation at $10,000 \times \mathrm{g}$ for $20 \mathrm{~min}$ at $4^{\circ} \mathrm{C}$ and filtered through a $0.22 \mu \mathrm{m}$ microfiltration membrane. HPLC qualitatively analysed the composition of the hydrolysate. The HPLC method was in line with the method described in 2.2. A suitable glycosidase was selected based on the retention rate of STG (calculated by (1)) and hydrolysate yields (calculated by (2)).

$$
\begin{aligned}
& \mathrm{Y}_{1}=\frac{\mathrm{m}_{2}}{\mathrm{~m}_{1}} \times 100 \%, \\
& \mathrm{Y}_{2}=\frac{\mathrm{m}_{3} \mathrm{M}_{1}}{\mathrm{~m}_{1} \mathrm{M}_{2}} \times 100 \%,
\end{aligned}
$$

In equations (1) and (2), $\mathrm{Y}_{1}$ represents the retention rate of STG, $\mathrm{Y}_{2}$ represents the conversion rate of enzymatic hydrolysis products, $\mathrm{m}_{1}$ represents the weight of STG in the reaction solution at $0 \mathrm{~h}, \mathrm{~m}_{2}$ represents the weight of STG in the reaction solution at the end of the reaction, $\mathrm{m}_{3}$ represents the weight of sesaminol in the reaction solution at the end of the reaction, $\mathrm{M}_{1}$ represents the molecular weight of STG, and $\mathrm{M}_{2}$ represents the molecular weight of enzymatic hydrolysis products.

\subsection{Optimization of the enzymatic hydrolysis conditions}

The optimal conditions for the preparation of sesaminol from STG were determined by a single-factor test and $\mathrm{RSM}^{24,25)}$. Reaction time, temperature, $\mathrm{pH}$, substrate concentration and enzyme concentration were selected as variables in the single-factor test of the experimental design. The levels of these five factors were set as follows: reaction times of $0.5-12.0 \mathrm{~h}$; temperatures of $20-60^{\circ} \mathrm{C}$; $\mathrm{pH}$ of 3.0-7.0; substrate concentration of $1.0-3.0 \mathrm{mg} / \mathrm{mL}$; and enzyme concentration of 10-30 mg.

According to the results of the single-factor test, $\mathrm{pH}\left(\mathrm{x}_{1}\right)$, temperature $\left(\mathrm{x}_{2}\right)$ and reaction time $\left(\mathrm{x}_{3}\right)$ were chosen for optimization by RSM. The levels of independent variables are shown in Table 2.

\subsection{DPPH free radical scavenging activity assays}

The abilities of 10 compounds to scavenge DPPH free radicals were assessed according to the method of Yeo et $a l .{ }^{26)}$. First, $100 \mu \mathrm{L}$ samples of different concentrations were added to a 96 -well microplate, and $100 \mu \mathrm{L}$ DPPH in $80 \%$ ethanol $(0.2 \mathrm{mmol} / \mathrm{L})$ was prepared in each well and mixed through the flat plate oscillation period. The mixture was incubated at room temperature for $30 \mathrm{~min}$ in the dark. The absorbance was measured using an Infinite M Nano absorbance plate reader (Tecan Group Ltd., Zürich, Switzerland) at $517 \mathrm{~nm}$. The DPPH radical scavenging capacity was calculated using the following equation:

$$
\mathrm{DPPH}_{\text {scavenging ability }}=\left(1-\frac{\mathrm{A}_{\text {sample }}-\mathrm{A}_{\text {sample background }}}{\mathrm{A}_{\text {control }}}\right) \times 100 \% \text { (3) }
$$

where $\mathrm{A}_{\text {sample }}$ is the absorbance of the sample and $\mathrm{DPPH}$,

Table 1 The optimum conditions of the enzymatic hydrolysis of STG by four enzymes.

\begin{tabular}{lcccc}
\hline \multicolumn{1}{c}{ Enzyme } & Temperature $/{ }^{\circ} \mathrm{C}$ & $\mathrm{pH}$ & Time $/ \mathrm{h}$ & Dosage $/ \mathrm{mg} / \mathrm{mL}$ \\
\hline$\beta$-galactosidase & 50.0 & 5.0 & 8.0 & 15.0 \\
$\beta$-glucosidase & 50.0 & 5.0 & 8.0 & 4.0 \\
$\beta$-glucanase & 37.0 & 5.0 & 8.0 & 2.4 \\
Cellulase & 55.0 & 4.6 & 8.0 & 171.4 \\
\hline
\end{tabular}


Table 2 Coded levels and actual values (in parentheses) of the variables in Box-Behnken design.

\begin{tabular}{crrrr}
\hline Run & \multicolumn{1}{c}{$\mathrm{x}_{1}$} & \multicolumn{1}{c}{$\mathrm{x}_{2}$} & $\mathrm{x}_{3}$ & $\mathrm{Y}(\%)$ \\
\hline 1 & $-1(4.5)$ & $-1(45.0)$ & $0(4.0)$ & 79.24 \\
2 & $-1(4.5)$ & $1(55.0)$ & $0(4.0)$ & 77.12 \\
3 & $1(5.5)$ & $-1(45.0)$ & $0(4.0)$ & 92.56 \\
4 & $1(5.5)$ & $1(55.0)$ & $0(4.0)$ & 92.63 \\
5 & $0(5.0)$ & $-1(45.0)$ & $-1(3.5)$ & 85.78 \\
6 & $0(5.0)$ & $-1(45.0)$ & $1(4.5)$ & 85.92 \\
7 & $0(5.0)$ & $1(55.0)$ & $-1(3.5)$ & 84.13 \\
8 & $0(5.0)$ & $1(55.0)$ & $1(4.5)$ & 84.21 \\
9 & $-1(4.5)$ & $0(50.0)$ & $-1(3.5)$ & 83.89 \\
10 & $1(5.5)$ & $0(50.0)$ & $-1(3.5)$ & 98.88 \\
11 & $-1(4.5)$ & $0(50.0)$ & $1(4.5)$ & 84.13 \\
12 & $1(5.5)$ & $0(50.0)$ & $1(4.5)$ & 96.73 \\
13 & $0(5.0)$ & $0(50.0)$ & $0(4.0)$ & 95.94 \\
14 & $0(5.0)$ & $0(50.0)$ & $0(4.0)$ & 95.62 \\
15 & $0(5.0)$ & $0(50.0)$ & $0(4.0)$ & 95.88 \\
\hline
\end{tabular}

$\mathrm{A}_{\text {sample background }}$ is the absorbance of the sample background (sample and ethanol instead of DPPH), and $\mathrm{A}_{\text {control }}$ is the absorbance of the control(DPPH and $100 \mu \mathrm{L}$ of ethanol instead of sample).

\subsection{ABTS free radical scavenging activity assays}

The method of Re et al. was used to determine ABTS assay $^{27)} .20 \mu \mathrm{L}$ sample solution and $200 \mu \mathrm{L}$ of working solution were added to the 96-well plate. The mixture was then mixed on the plate vibrator and reacted for 6 min in the dark at room temperature. An Infinite M Nano absorbance plate reader was used to observe the absorbance of the sample solution at $734 \mathrm{~nm}$. The sample solution with a certain gradient concentration was used to determine the ABTS scavenging activity. The $\mathrm{IC}_{50}$ value was calculated by SPSS analysis.

$$
\mathrm{ABTS}_{\text {scavenging ability }}=\left(1-\frac{\mathrm{A}_{\text {sample }}}{\mathrm{A}_{\text {control }}}\right) \times 100
$$

where $A_{\text {control }}$ is the absorbance of methanol and ABTS radicals and $A_{\text {sample }}$ is the absorbance of ABTS radicals in the sample.

\subsection{Ferric reducing antioxidant power (FRAP)}

The FRAP capacity was estimated following Benzie et $a l .{ }^{28)}$ as described with slight modification. Fresh FRAP reagent $(150 \mu \mathrm{L})$ was pipetted into a well of a 96-well plate and mixed with $30 \mu \mathrm{L}$ of $1 \mathrm{mg} / \mathrm{mL}$ sample solution. The absorbance of the blank sample $(150 \mu \mathrm{L}$ FRAP reagent and 30 $\mu \mathrm{L}$ distilled water) was recorded after incubation for $30 \mathrm{~min}$ at $37^{\circ} \mathrm{C}$. A standard curve was plotted by measuring the absorbance of 0-2 mmol $\mathrm{FeSO}_{4}$ at $593 \mathrm{~nm}$. The results are presented in $\mu \mathrm{mol} \mathrm{FeEq/g}$ of sample, according to a standard curve of $\mathrm{FeSO}_{4}$.

\subsection{D-QSAR of sesaminol}

3D-QSAR helps to gain insight into the relationship between specific bioactivity and molecular structure. As a classic 3D-QSAR technique, CoMFA illuminates the effect of steric and electrostatic fields of a set of aligned compounds on their biological activity by associating these 3D fields with the corresponding experimental activities of ligands interacting with a common target receptor ${ }^{29)}$. CoMFA has been applied to demonstrate the structure-activity relationships ${ }^{30)}$.

Sesaminol, STG, SDG, SMG, asarinin, sesamin, sesamolin, paulownin, methylophiopogon flavone A and methylophiopogonanone A were utilized to construct the CoMFA model by SYBYL-X 2.1.1 software. The molecular structures of the 10 compounds were drawn with a sketch module and energy minimization using a conjugate-gradient minimizer. The MMFF94 method was used to calculate the partial atomic charges of all the compounds, and then the Powell conjugated gradient algorithm method was utilized to optimize their geometry. Moreover, $0.0005 \mathrm{kcal} /$ (mol $\AA$ ) was selected as the energy convergence criterion, and the maximum iteration was set as 10,000 to construct a steady conformation ${ }^{7)}$.

To construct the CoMFA model based on the $\mathrm{pIC}_{50}$ of $\mathrm{DPPH}$, sesaminol was chosen as a template molecule in the molecule alignment stage because it is the strongest DPPH scavenging compound; other compounds were aligned on the framework structure of 1,3-benzodioxole in the tem- 
plate molecule. To build the CoMFA model based on the $\mathrm{pIC}_{50}$ of ABTS, methylophiopogonanone A was selected as the template molecule in the molecule alignment stage because it is the strongest ABTS scavenging compound (Fig. 4(a)), another operation is to refer to the method of the CoMFA model based on the $\mathrm{pIC}_{50}$ of DPPH.

The linear correlation between the biological activity and the CoMFA model was assessed by Partial least squares (PLS) analysis. In this study, leave-one-out (LOO) cross-validation procedures were used to determine the optimal number of components and cross-validation correlation coefficient $\left(\mathrm{Q}^{2}\right)$, while non-cross-validated analysis was used to calculate the non-cross-validated correlation coefficient $\left(\mathrm{R}^{2}\right)$, standard error of estimate (ESS), and $\mathrm{F}$-value ${ }^{31}$. The CoMFA model was regarded as acceptable when $\mathrm{Q}^{2}$ and $\mathrm{R}^{2}$ were greater than 0.5 and 0.6 , respectively ${ }^{30}$.

\subsection{Statistical analysis}

All the tests were performed in triplicate. The statistical significance was determined by the level of $p<0.05$. There was no significant difference between the values with the same letters in one curve. SAS software(Version 8.5, North Carolina, USA) and SPSS software (version 20.0; SPSS, Chicago, IL, USA) were applied to the experimental design and statistical analysis.

\section{Results and Discussion}

\subsection{Preparation and identification of STG, SDG, SMG and sesaminol}

STG, SDG, SMG and sesaminol were successfully obtained by column chromatography and liquid-liquid extraction. Their purity was determined by HPLC to be $98.17 \%$, $98.19 \%, 98.53 \%$ and $99.35 \%$, respectively. The contents of the solution mixture were also determined by HPLC, including the levels of STG, SDG, SMG and sesaminol. The HPLC chromatogram is shown in Fig. 1A. As shown in Figs. 1B-1E, fragments at $\mathrm{m} / z$ 879.2479, 717.1979, 555.1470 and 393.0940 were the $[\mathrm{M}+\mathrm{Na}]^{+}$ions, and the molecular weights of the corresponding compounds were 856.2581 , 694.2 081, 532.1572 and 370.1042 , which were in agreement with previous reports ${ }^{24,32)}$. The results showed that STG could be obtained from sesame cake. STG could be a raw material that can be used for the preparation of SMG, SDG and sesaminol. Otherwise, the four compounds obtained could be used in the following test as standard and raw material.

\subsection{Effect of different enzymes on the conversion rate of sesaminol}

As shown in Fig. $2 \mathrm{~A}, \beta$-galactosidase, $\beta$-glucosidase, $\beta$-glucanase and cellulase were reacted with STG under the optimal conditions for $8.0 \mathrm{~h}$. Sesaminol and SDG were the main products, and their final conversion rates were as follows: the sesaminol exhibited conversion rates of $94.62 \%, 5.16 \%, 1.86 \%, 4.04 \%$ while SDG exhibited rates of $0 \%, 85.84 \%, 78.21 \%, 86.15 \%$ in the reactions with the four different enzymes. The highest conversion rate of sesaminol appeared in the reaction involving $\beta$-galactosidase hydrolysate. However, most of the STG was converted to SDG by $\beta$-glucosidase, $\beta$-glucanase and cellulase. These results depend on the substrate structure and cleavage specificity of the enzyme. The structure of the sesaminol glycoside was sesaminol 2'-O- $\beta$-D-glucopyranosyl- (1-2)-O$\left[\beta\right.$-D-glucopyranosyl-(1-6) ]- $\beta$-D-glucopyranoside $(\mathrm{STG})^{21)}$. $\beta$-Galactosidase is an exoglycosidase that can degrade $\beta$-glycosidic bonds, including $\beta$-(1-2)-glycosidic bonds, $\beta$ (1-6)-glycosidic bonds, and $\beta$-(1-4)-glycosidic bonds ${ }^{25}$. However, $\beta$-glucosidase, $\beta$-glucanase and cellulase preferentially cleave glycosidic bonds to terminal nonreducing residues in $\beta$-glucosides, $\beta$-(1-6)-glycosidic bonds and $\beta$ (1-4)-glycosidic bonds, respectively ${ }^{33,34}$. $\beta$-Galactosidase showed higher performance in the preparation of sesaminol by hydrolysing STG than the other enzymes ${ }^{35}$. According to the results, it can be inferred that $\beta$-galactosidase was suitable to prepare sesaminol from STG effectively.

\subsection{Effect of reaction time on the conversion rate of sesa- minol}

The retention of STG and the conversion of its hydrolysis products are shown in Fig. 2B. A dramatic change in the content of each component occurred in the first $1.0 \mathrm{~h}$ during enzymatic hydrolysis. The STG rapidly disappeared after $0.5 \mathrm{~h}$. The SDG conversion rate reached a peak at $84.69 \%$ at $0.25 \mathrm{~h}$ and then decreased to $0 \%$ at $1.0 \mathrm{~h}$. The conversion rate of SMG reached a maximum of $19.91 \%$ at $0.5 \mathrm{~h}$ and subsequently gradually disappeared at $3.0 \mathrm{~h}$. The conversion rate of sesaminol significantly increased to $84.15 \%$ within $1.0 \mathrm{~h}$ and continued to increase to a high point at $4.0 \mathrm{~h}$. Therefore, the reaction path from STG to sesaminol included two intermediate products, SDG and SMG, glucose. The study results were consistent with those of Nair et al. ${ }^{36)}$. The conversion rate of sesaminol did not significantly increase over an $8 \mathrm{~h}$ period. Thus, $4.0 \mathrm{~h}$ was selected as the proper reaction time. The reaction takes less time than those using $\beta$-glucosidase and microbial fermentation to prepared sesaminol ${ }^{13,20,211}$.

\subsection{Effect of reaction temperature on the conversion rate of sesaminol}

The effect of temperature $\left(20-60^{\circ} \mathrm{C}\right)$ on the conversion rate of sesaminol from STG $(1.5 \mathrm{mg} / \mathrm{mL})$ by $\beta$-galactosidase at pH 5.0 after incubation for $4 \mathrm{~h}$ is presented in Fig. 2C. The STG and SDG disappeared at the end of the reaction. The lowest conversion rate of sesaminol was $29.4 \%$ at $20^{\circ} \mathrm{C}$. At the same temperature, the SMG conversion rate reached $69.0 \%$. As the reaction temperature gradually in- 

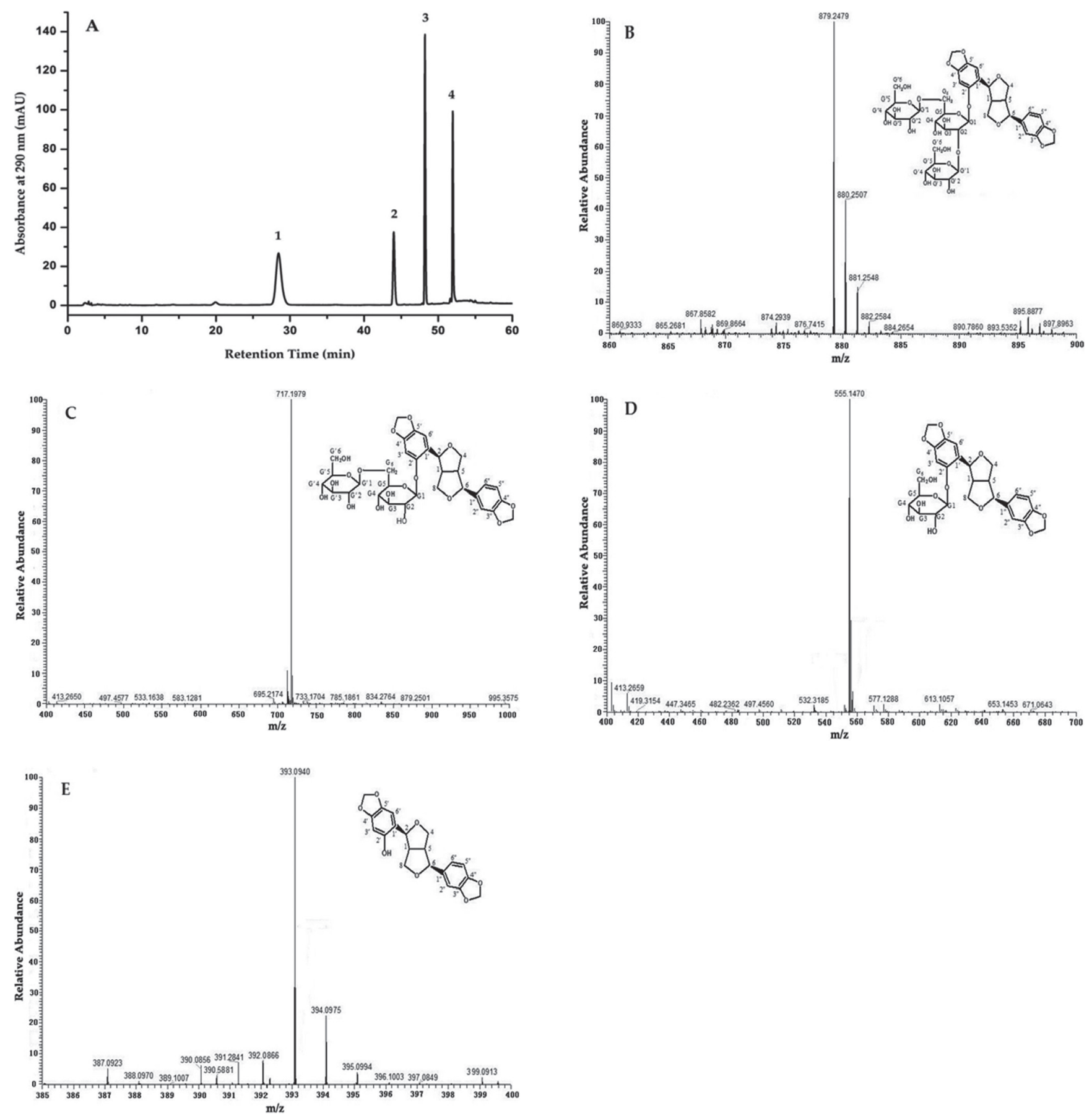

Fig. 1 HPLC chromatograms analysis of STG and its hydrolysis products (A, Peak 1, STG; Peak 2, SDG; Peak 3, SMG; Peak 4, Sesaminol); ESI-MS spectra of STG and its hydrolysis products (B, peak 1, STG, $m / z 879.2479,[\mathrm{M}+\mathrm{Na}]^{+}$; C, peak 2 , $\mathrm{SDG}, \mathrm{m} / z$ 717.1979, $[\mathrm{M}+\mathrm{Na}]^{+}$; D, peak $3, \mathrm{SMG}, \mathrm{m} / z 555.1470,[\mathrm{M}+\mathrm{Na}]^{+}$; E, peak 4, sesaminol, $\mathrm{m} / z 393.0940,[\mathrm{M}+$ $\mathrm{Na}]^{+}$).

creased to $50^{\circ} \mathrm{C}$, the conversion rate of sesaminol significantly increased to a maximum of $95.3 \%(p<0.05)$, while the conversion rate of SMG decreased to a minimum of $3.0 \%$. The conversion rate of sesaminol significantly decreased as the temperature exceeded $60^{\circ} \mathrm{C}$, which was related to the enzyme denaturation caused by high tem- perature. This result was consistent with the report that the optimum temperature of $\beta$-galactosidase from Aspergillus oryzae was in the range of 45 to $55^{\circ} \mathrm{C}^{33)}$. Therefore, $50^{\circ} \mathrm{C}$ was selected as the optimum reaction temperature. 
A
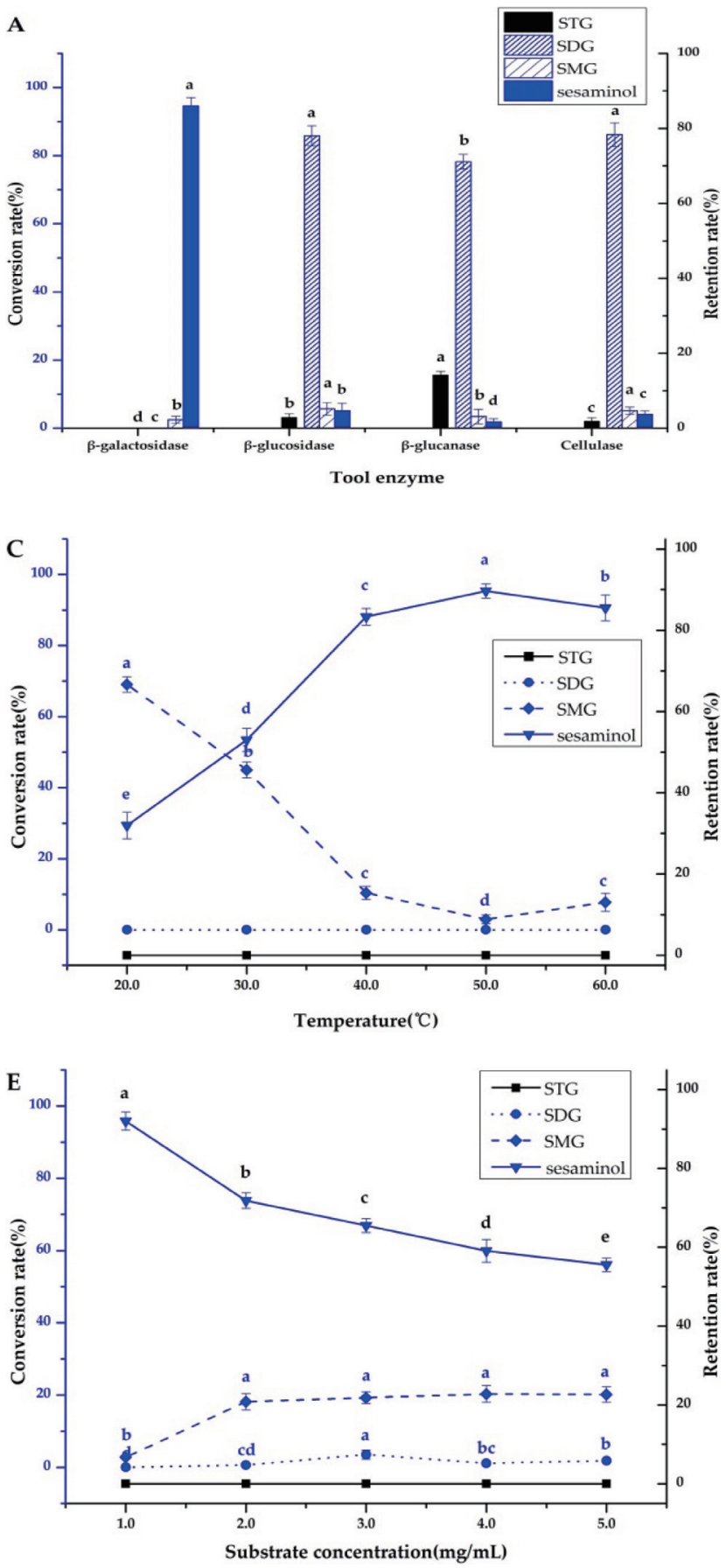
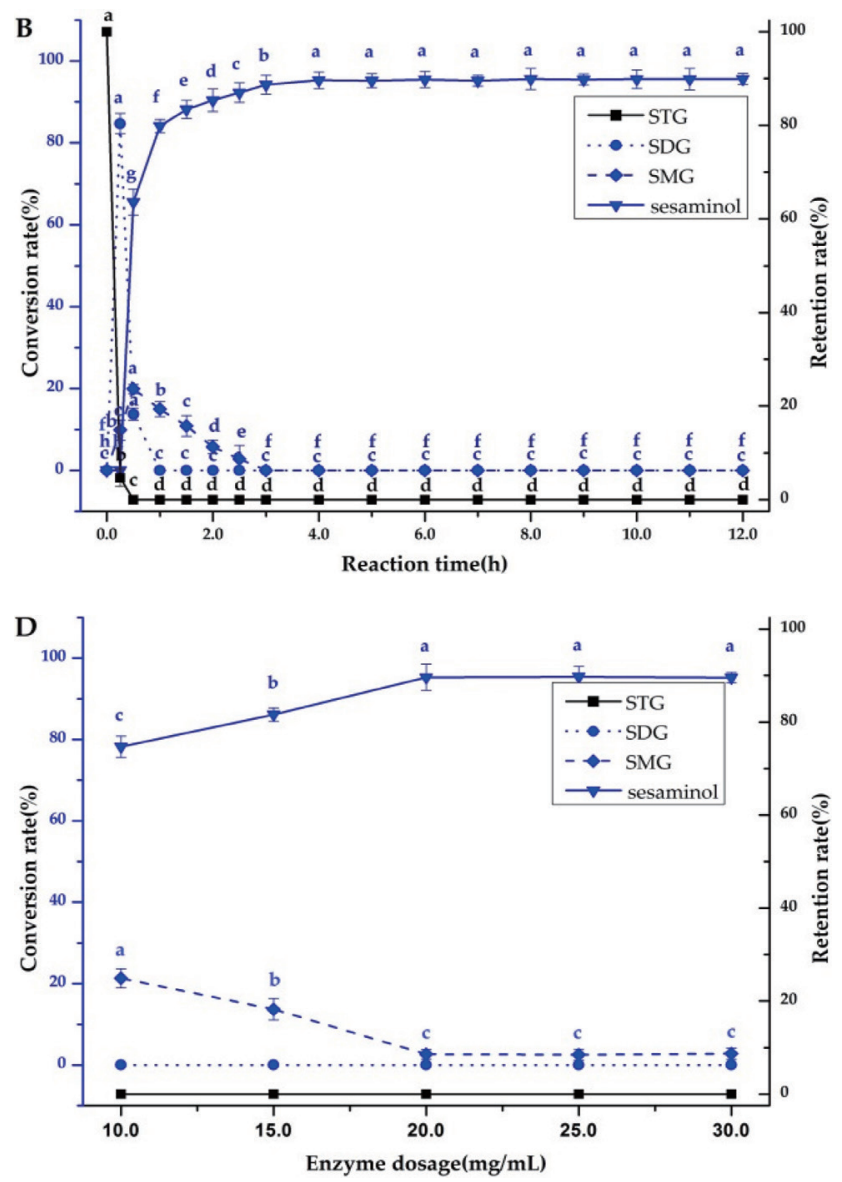

F

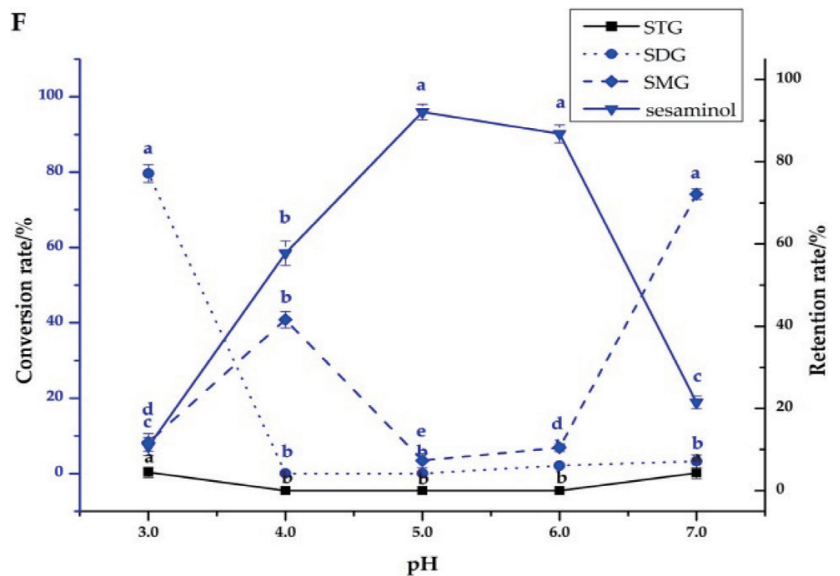

Fig. 2 Effect of different enzymes(A), reaction time(B), reaction temperature(C), enzyme dosage(D), substrate concentration $(\mathrm{E})$ and $\mathrm{pH}(\mathrm{F})$ on the conversion rate of sesaminol. (Different lowercase letters on different columns indicate significant difference $(p<0.05)$.)

\subsection{Effect of enzyme dosage on the conversion rate of sesaminol}

The influence of the enzyme dosage on the conversion rate of sesaminol is shown in Fig. 2D. When the enzyme dosage was increased from $10 \mathrm{mg} / \mathrm{mL}$ to $20 \mathrm{mg} / \mathrm{mL}$, the STG and SDG disappeared, the conversion rate of SMG ranged from $21.3 \%$ to $2.7 \%$, and the conversion rate of sesaminol significantly increased to $95.4 \%$. However, when the enzyme dosage increased from $20 \mathrm{mg} / \mathrm{mL}$ to $30 \mathrm{mg} / \mathrm{mL}$, the conversion rate of sesaminol did not significantly change. Considering the cost of the enzyme, the enzyme dosage was set at $20.0 \mathrm{mg} / \mathrm{mL}$. 


\subsection{Effect of substrate concentration on the conversion rate of sesaminol}

Substrate concentration is one of the main affecting factors for enzymatic hydrolysis reaction ${ }^{37)}$. As shown in Fig. 2E, when the substrate concentration was $1.0 \mathrm{mg} / \mathrm{mL}$, STG was completely enzymatically hydrolysed, and the conversion rate of sesaminol was up to $95.8 \%$ with a small amount of residual SMG. As the substrate concentration increased, the conversion rate of sesaminol significantly decreased, and the conversion rates of the SDG and SMG slightly increased. Overall, these results indicate that 1.0 $\mathrm{mg} / \mathrm{mL}$ was the optimal substrate concentration.

\subsection{Effect of reaction $\mathrm{pH}$ on the conversion rate of sesa- minol}

As shown in Fig. 2F, the conversion rate of sesaminol ranged from $7.2 \%$ to $95.9 \%$ as the $\mathrm{pH}$ increased from 3.0 to 5.0. There was no significant difference between the conversion rate of sesaminol at $\mathrm{pH} 5.0$ and $6.0(p>0.05)$. However, the conversion rate of sesaminol remarkably decreased at $\mathrm{pH} 7.0(p<0.05)$. The highest conversion rates of SMG and SDG were $74.2 \%$ at $\mathrm{pH} 7.0$ and $79.6 \%$ at $\mathrm{pH}$ 3.0. Therefore, it was suitable for enzymatic hydrolysis of STG into sesaminol at $\mathrm{pH}$ 5.0-6.0. The optimal $\mathrm{pH}$ for sesaminol production with $\beta$-galactosidase was in agreement with the optimal $\mathrm{pH}$ range of 5.0-6.0 for ginsenoside $\mathrm{Rg}$ (3) hydrolysis ${ }^{38)}$.

\subsection{Response surface experimental results}

Three factors and three levels Box-Behnken design in- cluding 15 trials was used to assess the effect of hydrolysis factors, including $\mathrm{pH}\left(\mathrm{x}_{1}\right)$, temperature $\left(\mathrm{x}_{2}\right)$ and reaction time $\left(\mathrm{x}_{3}\right)$, on the conversion rate of sesaminol; the results of these trials were used to optimize these factors. The experimental results are shown in Table 2. The experimental data were analysed by multiple regression analysis, and a second-order polynomial Eq. (5) was used to describe the relationship between the independent variables and survey the conversion rate of sesaminol. The second-order equation (in coded format) was presented:

$$
\begin{aligned}
\mathrm{Y}= & 95.8133+7.0525 * \mathrm{x}_{1}-0.67625 * \mathrm{x}_{2}+0.2113 * \mathrm{x}_{3}- \\
& 2.2642 * \mathrm{x}_{1}{ }^{2}+0.5475 \mathrm{x}_{1} * \mathrm{x}_{2}-0.5975 \mathrm{x}_{1} * \mathrm{x}_{3}-8.161 \\
& 7 \mathrm{x}_{2}{ }^{2}-0.015 \mathrm{x}_{2}{ }^{*} \mathrm{x}_{3}-2.6417 * \mathrm{x}_{3}{ }^{2}
\end{aligned}
$$

In Table 3 above, we can see the ANOVA results. The Model F-value was 362.8777. A p-value lower than 0.0001 indicates that the model was in line with the actual data. The determination coefficient $\left(\mathrm{R}^{2}\right)$ was 0.9985 , which suggested that only $0.15 \%$ of the total variation was not fitted with the model. The Lack of Fit was $0.082943(>0.05)$, indicating that the lack of fit was not significant. The $p$-values of the linear coefficient $\left(\mathrm{x}_{1}, \mathrm{x}_{2}\right)$ and quadratic coefficients $\left(\mathrm{x}_{1}{ }^{2}, \mathrm{x}_{2}{ }^{2}, \mathrm{x}_{3}{ }^{2}\right)$ were less than 0.05 , implying the significant effects of these factors on the conversion rate.

3.8.1 Response surface three-dimensional plots

To illustrate the intercorrelations between the three above factors and the conversion rate of sesaminol, a threedimensional response surface was built(Fig. 3). When the

\begin{tabular}{|c|c|c|c|c|c|c|}
\hline Source & Sum of squares & DF & Mean square & F-value & Probability & Significance \\
\hline Model & 673.8803 & 9 & 74.87559 & 362.8777 & 0.0001 & $* *$ \\
\hline $\mathrm{x}_{1}$ & 397.902 & 1 & 397.902 & 1928.396 & 0.0001 & $* *$ \\
\hline $\mathrm{x}_{2}$ & 3.658513 & 1 & 3.658513 & 17.73065 & 0.008402 & $* *$ \\
\hline $\mathrm{x}_{3}$ & 0.357013 & 1 & 0.357013 & 1.730229 & 0.245469 & \\
\hline $\mathrm{x}_{1} * \mathrm{x}_{2}$ & 1.199025 & 1 & 1.199025 & 5.810966 & 0.060819 & \\
\hline $\mathrm{x}_{1} * \mathrm{x}_{3}$ & 1.428025 & 1 & 1.428025 & 6.920794 & 0.060812 & \\
\hline $\mathrm{x}_{2} * \mathrm{x}_{3}$ & 0.0009 & 1 & 0.0009 & 0.004362 & 0.949902 & \\
\hline $\mathrm{x}_{1} * \mathrm{x}_{1}$ & 18.92843 & 1 & 18.92843 & 91.73493 & 0.00021 & $* *$ \\
\hline $\mathrm{x}_{2} * \mathrm{x}_{2}$ & 245.955 & 1 & 245.955 & 1191.998 & 0.0001 & $* *$ \\
\hline $\mathrm{x}_{3} * \mathrm{x}_{3}$ & 25.76641 & 1 & 25.76641 & 124.8746 & 0.0001 & $* *$ \\
\hline Residual & 1.031692 & 5 & 0.206338 & & & \\
\hline Lack of fit & 0.973825 & 3 & 0.324608 & 11.21918 & 0.082943 & \\
\hline Pure error & 0.057867 & 2 & 0.028933 & & & \\
\hline Cor total & 674.912 & 14 & & & & \\
\hline \multicolumn{3}{|c|}{$\mathrm{R}^{2}=0.9985$} & \multicolumn{4}{|c|}{$\mathrm{R}_{\mathrm{Adj}}^{2}=0.9957$} \\
\hline
\end{tabular}
effect of two factors was plotted, the other factor was

Table 3 ANOVA for response surface quadratic model.

(Note: *Significant difference $(p<0.05) ; * *$ Remarkable difference $(p<0.01))$ 


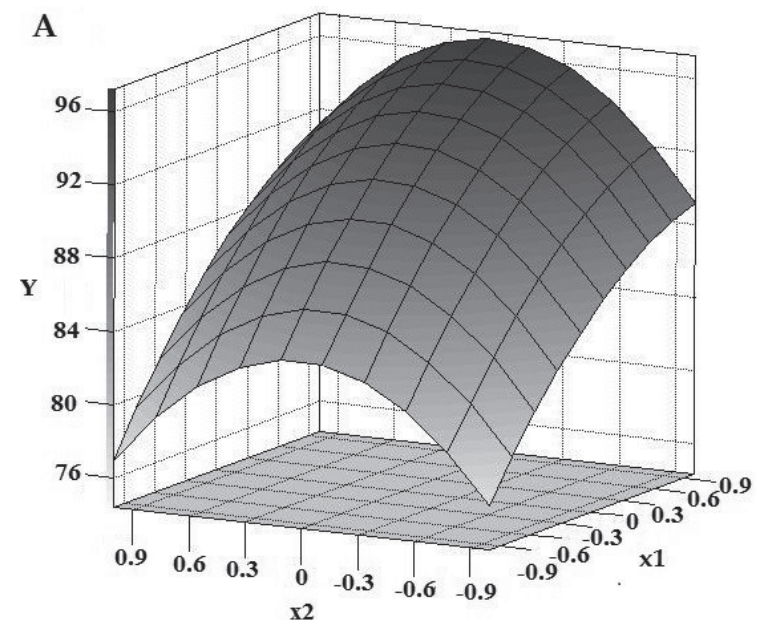

Fixed levels: $x 3=-1$
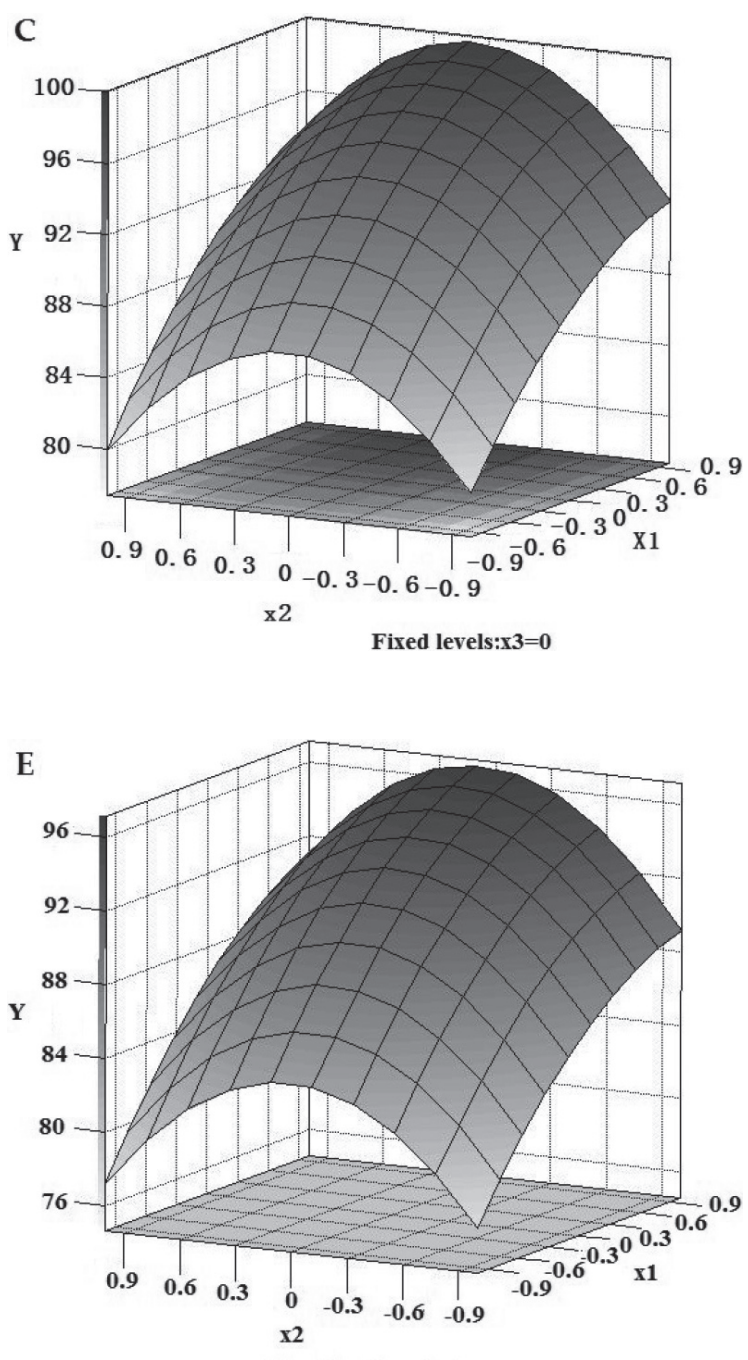

Fixed levels: $x 3=1$
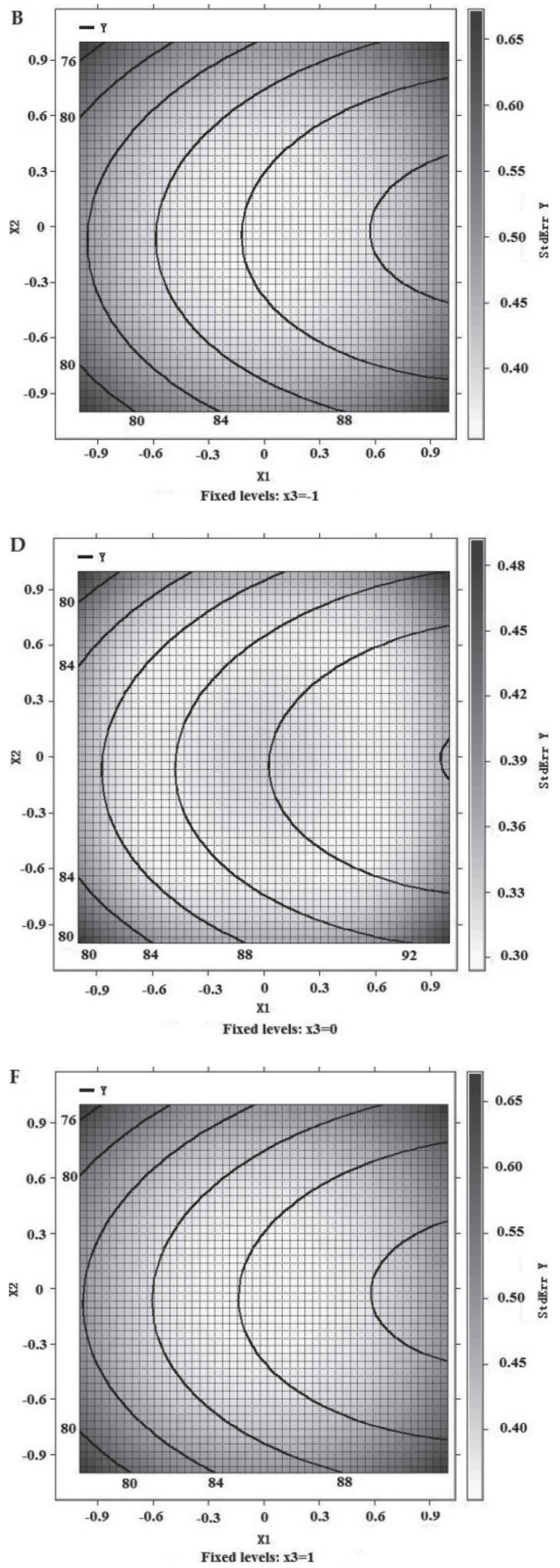

Fig. 3 The effect of $\mathrm{pH}$ and temperature interaction on the conversion rate of sesaminol at different levels. 
fixed. In the investigation range, $\mathrm{pH}$ and temperature were significant factors, so the curve of the response surface and contour map of the conversion rate of sesaminol at fixed reaction times were observed. Figures $3 \mathrm{~A}$ and $3 \mathrm{~B}$ shows that as the reaction temperature was fixed, and that the conversion rate of sesaminol gradually increased and then tended to be stable with increasing $\mathrm{pH}$. The enzyme activity remained stable because the $\mathrm{pH}$ was near the optimum $\mathrm{pH}$ range for the enzyme. This result was in line with the single-factor test studies. When $\mathrm{pH}$ was the fixed variable, the conversion rate of sesaminol increased when the reaction temperature was raised from $45^{\circ} \mathrm{C}$ to $50^{\circ} \mathrm{C}$ and then decreased when the reaction temperature was raised from $50^{\circ} \mathrm{C}$ to $55^{\circ} \mathrm{C}$ because high temperature leads to enzyme denaturation, so enzyme activity decreased ${ }^{38,39)}$. The trend of sesaminol conversion at $4.0 \mathrm{~h}$ and $4.5 \mathrm{~h}$ was similar to that at $3.5 \mathrm{~h}$ (Figs. 3C-3F).

3.8.2 Verification of optimization

The optimum conditions predicted by SAS software were as follows: the $\mathrm{pH}$ value was 5.67 , the reaction temperature was $49.66^{\circ} \mathrm{C}$, the reaction time was $3.91 \mathrm{~h}$, the substrate concentration was $1.0 \mathrm{mg} / \mathrm{mL}$, and the enzyme dosage was $20 \mathrm{mg} / \mathrm{mL}$. Under these conditions, the conversion rate of sesaminol was $100.42 \pm 0.52 \%$. For convenience of operation, the enzymatic hydrolysis process parameters were set to a $\mathrm{pH}$ of 5.5 , temperature of $50^{\circ} \mathrm{C}$, enzymatic hydrolysis time of $4.0 \mathrm{~h}$, substrate concentration of $1.0 \mathrm{mg} / \mathrm{mL}$, and an enzyme dosage of $20 \mathrm{mg} / \mathrm{mL}$. 3 parallel tests were conducted, and the conversion rate of sesaminol was $98.88 \pm$ $0.67 \%$. The result conformed to the predicted data. Therefore, the process parameters of the enzymatic hydrolysis of STG into sesaminol based on the response surface method are accurate and reliable. Compared with a previous report ${ }^{17,18,20)}$, the performance of the enzymatic preparation of sesaminol from STG improved due to the selection of the enzyme and the optimization of the hydrolysis conditions; the conversion rate of sesaminol rose from $48.90 \%$ to $98.88 \%$, the reaction time decreased to $1 / 6$ of previous reports $^{20)}$. The enzymatic hydrolysis technology not only reduced the nutrition and edible values of sesame oil, but also could improve the utilization rate and added value of sesame cake, which is a rich by-product of sesame oil industries $^{17,18)}$.

\subsection{D-QSAR of sesaminol and its derivative}

The antioxidant ability of sesaminol, STG, SDG, SMG, asarinin, sesamin, sesamolin, paulownin, methylophiopogonanone A and methylophiopogonone A was measured. The results of DPPH and ABTS radical scavenging ability tests and FRPA are shown in Table 4. Sesaminol exhibited excellent antioxidant activity in $\mathrm{DPPH}\left(\mathrm{IC}_{50}=0.0011 \mathrm{mg} / \mathrm{mL}\right)$, $\operatorname{ABTS}\left(\mathrm{IC}_{50}=0.0021 \mathrm{mg} / \mathrm{mL}\right)$ radical scavenging activities and FRAP (103.2998 mol/g) among sesaminol derivatives, which was also in accordance with a previous study ${ }^{40)}$.

To elucidate the effects of sterics and electrostatic fields on the antioxidant activity of sesaminol, CoMFA models based on $-\log \left(\mathrm{IC}_{50}\right.$ of $\left.\mathrm{DPPH}\right)$ and $-\log \left(\mathrm{IC}_{50}\right.$ of ABTS $)$ were established (Table 5). As seen in Table 6, the CoMFA model for $-\log \left(\mathrm{IC}_{50}\right.$ of $\left.\mathrm{DPPH}\right)$ and $-\log \left(\mathrm{IC}_{50}\right.$ of ABTS $)$ was successfully established based on $\mathrm{Q}^{2}>0.5\left(\mathrm{Q}_{\mathrm{DPPH}}{ }^{2}=0.558\right.$, $\left.\mathrm{Q}_{\mathrm{ABTS}}{ }^{2}=0.534\right)$. These models had good $\mathrm{R}^{2}$ values $\left(\mathrm{R}^{2}=\right.$ $1.000)$ with low standard errors of estimate $(<0.05)$ and a high $\mathrm{F}$ value $\left(\mathrm{F}_{\mathrm{DPPH}}=171737.028, \mathrm{~F}_{\mathrm{ABTS}}=8955.818\right)$. The CoMFA based on the DPPH scavenging activity has the highest $\mathrm{Q}^{2}$; moreover, it was reliable to evaluate the antioxidant activity of fat-soluble sesaminol by DPPH scavenging assay. Therefore, this paper only analysed and discussed the CoMFA model based on the DPPH activity results.

In Figs. 4A-4B, there are large green areas in the $1 \mathrm{H}$, $3 \mathrm{H}$-furo $[3,4-\mathrm{c}]$ furan group and $\mathrm{C}_{2}{ }$ " and $\mathrm{C}_{6}$ " positions of the substituent $R_{2}$, indicating that the introduction of substituents with larger groups here is beneficial to the improvement of activity. This observation also agrees with the experimental result, as the larger 5,7-dihydroxy-6,8dimethyl-4H-1-benzopyran-4-one group at the $\mathrm{R}_{2}$ position of methylophiopogonone A presented higher DPPH inhibi-

Table 4 The antioxidant activity of sesaminol and its derivatives.

\begin{tabular}{cccc}
\hline Name & $\mathrm{IC}_{50}$ ABTS $(\mathrm{mg} / \mathrm{mL})$ & $\mathrm{IC}_{50} \mathrm{DPPH}(\mathrm{mg} / \mathrm{mL})$ & $\mathrm{FRAP}(\mu \mathrm{mol} / \mathrm{g})$ \\
\hline sesaminol & 0.0021 & 0.0011 & 103.2998 \\
STG & 31.0174 & $9.39 \mathrm{E}+12$ & 56.0517 \\
SDG & 121140.9194 & 46707.9563 & 43.4433 \\
SMG & 5332.6395 & 598.6076 & 44.6696 \\
Asarinin & 57.3763 & 0.2128 & 37.0110 \\
Sesamin & $2.57 \mathrm{E}+05$ & $3.05 \mathrm{E}+10$ & 39.8636 \\
Sesamolin & $2.44 \mathrm{E}+06$ & $4.79 \mathrm{E}+18$ & 55.0709 \\
Paulownin & 34195.659 & 1009.6503 & 8.3261 \\
Methylophiopogonanone A & 0.0047 & 0.0097 & 91.3624 \\
Methylophiopogonone A & 0.0027 & 0.0042 & 98.6291
\end{tabular}


Table 5 The antioxidant activity and molecular formula of sesaminol and its derivatives.

\begin{tabular}{|c|c|c|c|c|c|c|}
\hline \multirow{2}{*}{ Name } & \multirow{2}{*}{$\mathrm{R}_{1}$} & \multirow{2}{*}{$\mathrm{R}_{2}$} & \multicolumn{2}{|c|}{$-\mathrm{LOG}\left(\mathrm{IC}_{50}\right.$ of $\left.\mathrm{DPPH}\right)$} & \multicolumn{2}{|c|}{$-\mathrm{LOG}\left(\mathrm{IC}_{50}\right.$ of ABTS $)$} \\
\hline & & & Observed & Predicted(SEM) & Observed & Predicted(SEM) \\
\hline Sesaminol & $-\mathrm{OH}$ & & 2.5445 & $2.5410(0.0035)$ & 2.2533 & $2.2270(0.0263)$ \\
\hline STG & & & -13.0400 & $-13.0220(-0.0180)$ & -1.5590 & $-1.5490(-0.0100)$ \\
\hline SDG & & & -4.8279 & $-4.8410(0.0131)$ & -5.2418 & $-5.2260(-0.0158)$ \\
\hline SMG & & & -3.0511 & $-3.0560(0.0049)$ & -4.0009 & $-4.0009(0.0000)$ \\
\hline Asarinin & $-\mathrm{H}$ & & 0.2215 & $0.2280(-0.0065)$ & -2.2093 & $-2.2070(-0.0023)$ \\
\hline Sesamin & $-\mathrm{H}$ & & -10.9346 & $-10.9410(0.0064)$ & -5.8610 & $-5.8630(0.0020)$ \\
\hline Sesamolin & $-\mathrm{H}$ & & -19.1118 & $-19.1120(0.0002)$ & -6.8186 & $-6.8200(0.0014)$ \\
\hline Paulownin & $-\mathrm{H}$ & & -3.4355 & $-3.4500(0.0145)$ & -4.9653 & $-4.9560(-0.0093)$ \\
\hline Methylophiopogonanone A & $-\mathrm{H}$ & & 1.5440 & $1.5290(0.0150)$ & 1.8642 & $1.7940(0.0702)$ \\
\hline Methylophiopogonone A & $-\mathrm{H}$ & & 1.9085 & $1.9420(-0.0335)$ & 2.1030 & $2.1940(-0.0910)$ \\
\hline
\end{tabular}

Note: Standard error of means (SEM)

tory activity than sesamin. There is a yellow region at the $\mathrm{R}_{1}$ position, indicating that smaller groups would enhance the antioxidant activity. The smaller $-\mathrm{OH}$ at the $\mathrm{R}_{1}$ position of sesaminol presented better DPPH inhibitory activity than did SMG, SDG and STG. This conclusion obeyed the scavenging mechanism of the DPPH radical; that is, the larger the steric hindrance of the compound was, the more challenging it was for to come into contact with the un- paired electron of the intermediate $\mathrm{N}$ atom in the $\mathrm{DPPH}$ radical through the spatial barrier of the three benzene rings of $\mathrm{DPPH}^{27)}$.

In Figs. $4 C$ and $4 D$, the red region appears at the $R_{1}$ position, indicating that the introduction of more electronegative groups here is conducive to the improvement of the compound activity. This finding is in line with the experimental data, as the negatively charged -OH group at the $\mathrm{R}_{1}$ 
Table 6 Statistical parameters for the fitting of the CoMFA model for sesaminol and its derivatives.

\begin{tabular}{ccc}
\hline Parameter & $\begin{array}{c}\text { CoMFA based on } \\
-\log \left(\mathrm{IC}_{50} \text { of } \mathrm{DPPH}\right)\end{array}$ & $\begin{array}{c}\text { CoMFA based on } \\
-\log \left(\mathrm{IC}_{50} \text { of ABTS }\right)\end{array}$ \\
\hline $\mathrm{NC}^{1}$ & 5 & 4 \\
$\mathrm{Q}^{2}$ & 0.558 & 0.534 \\
$\mathrm{R}^{2}$ & 1.000 & 1.000 \\
$\mathrm{~F}$ value & 171737.028 & 8955.818 \\
Standard error of estimate & 0.023 & 0.055 \\
The contribution of steric field & 0.650 & 0.720 \\
The contribution of electrostatic field & 0.350 & 0.280 \\
\hline
\end{tabular}

$\mathrm{NC}^{1}$ represents optimal number of principal components

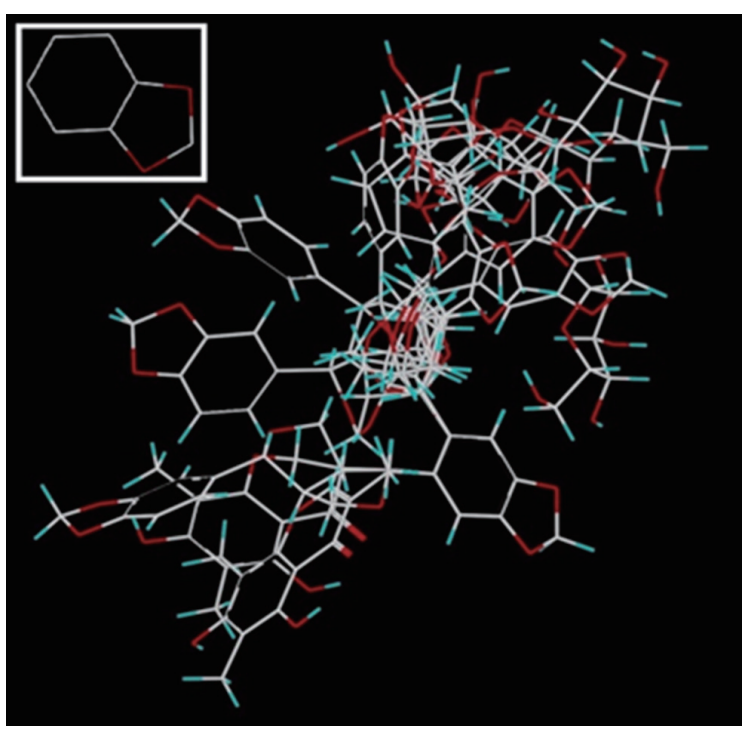

(a)

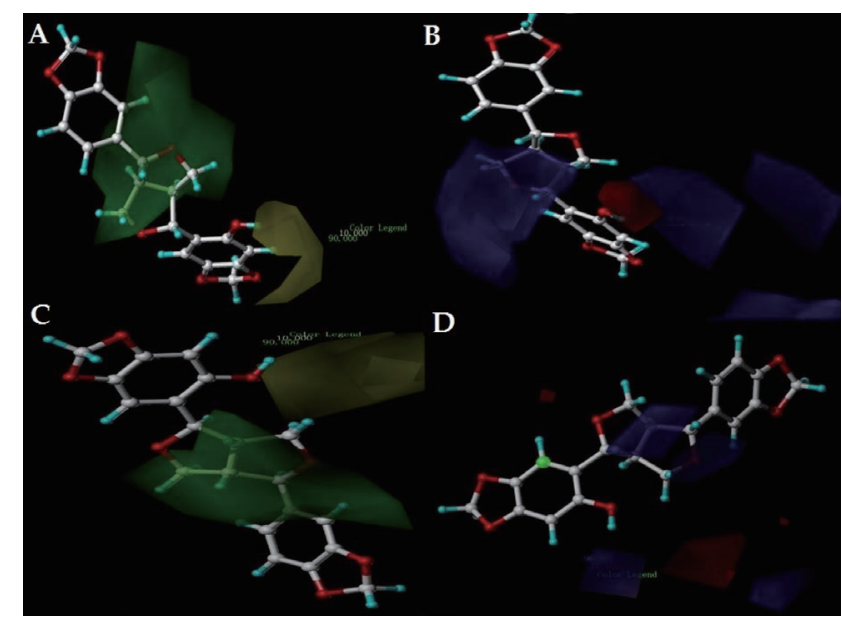

(b)

Fig. 4 (a) The common structure of 10 compounds used for the alignment and the overall alignment of the molecules used in the 3D-QSAR study; (b) Steric and electrostatic contour maps of the CoMFA model of sesaminol( (A) Steric contour map of the CoMFA model based on $-\log \left(\mathrm{IC}_{50}\right.$ of DPPH), (B) Electrostatic contour map of the CoMFA model $-\log \left(\mathrm{IC}_{50}\right.$ of $\left.\mathrm{DPPH}\right)$, (C) Steric contour map of the CoMFA model based on $-\log \left(\mathrm{IC}_{50}\right.$ of ABTS), (D) Electrostatic contourmap of the CoMFA model $-\log \left(\mathrm{IC}_{50}\right.$ of ABTS $)$.)

position of sesaminol resulted in higher DPPH inhibitory activity than that of sesamin, whose $R_{1}$ position was occupied by the less negatively charged $-\mathrm{H}$. A large blue area appeared in the 1H, 3H-furo [3,4-c] furan group of substituent $R_{2}$, indicating that the introduction of positively charged groups in the region was beneficial to the increase in the antioxidant activity of the compound. This increase in activity is because the introduction of a positive charge in this region can increase the rejection of DPPH radicals and increase the probability of DPPH radicals coming into contact with the compound from $\mathrm{R}_{1}(-\mathrm{OH})$ to improve the scavenging ability of DPPH radicals. Combined with the results of the steric field and electrostatic field analysis, the data indicated that $-\mathrm{OH}$ at the sesaminol $\mathrm{R}_{1}$ position was the active centre of DPPH free radical scavenging by sesaminol, and the result was in good agreement with a previous report that found that $-\mathrm{OH}$ increased the activity of flavonoids ${ }^{16)}$.

\section{Conclusions}

This study investigated the preparation method and structure-activity relationship of sesaminol. The results showed that $\beta$-galactosidase was a suitable enzyme to prepare sesaminol from STG. The optimal enzymatic hydrolysis conditions were established. In addition, the transformation rules of sesaminol, SMG and SDG were investi- 
gated to further reveal the mechanism of enzymatic hydrolysis. Furthermore, compared to other sesaminol derivatives, sesaminol has excellent scavenging capacity for DPPH, ABTS and FRAP. CoMFA models were developed according to $-\log \left(\mathrm{IC}_{50}\right.$ of $\left.\mathrm{DPPH}\right)$ and $-\log \left(\mathrm{IC}_{50}\right.$ of $\left.\mathrm{ABTS}\right)$. The active site of sesaminol tended to be located on the hydroxyl group of the benzene ring $\left(\mathrm{R}_{1}\right.$ position $)$. This study not only provides a short-time and effective method to prepare sesaminol, reveals the structure-activity relationship of sesaminol, but also provides theoretical basis to design the novel compound. The results are expected to provide more evidence for the utility of sesame as an antioxidant functional food.

\section{Author Contributions}

Gao, J.H.: Conceptualization, Data curation, Writingoriginal draft, Software, Funding acquisition. Wang, R.D.: Formal analysis, Investigation, Writing-review \& editing. Lu, X.: Conceptualization, Methodology, Software, Writingreview \& editing. Jia, C.: Formal analysis, Resources, Software. Sun, Q.: Validation, Project administration. Huang, J.N.: Funding acquisition, Supervision, Resource. Wei, S.L.: Methodology, Software. Ma, L.: Visualization, Methodology.

\section{Acknowledgments}

The research was funded by the earmarked fund for Science and Technology of Henan Province (Grant No. 192102110109, 212102110075) and National Technology System for Special Oilseed Industry (Grant No. CARS-14-130).

\section{References}

1) Matschke, V.; Theiss, C.; Matschke, J. Oxidative stress: The lowest common denominator of multiple diseases. Neural Regen Res. 14, 238-241 (2019).

2) Soomro, S. Oxidative stress and inflammation. Open J. Immunol. 9, 1-20 (2019).

3) Fu, Y.; Chung, F.L. Oxidative stress and hepatocarcinogenesis. Hepatoma Res. 4, 39 (2018).

4) Ester, P.G.; Rosa, B.; Margarita, C.; Eva, C. Oxidative stress damage and oxidative stress responses in the choroid plexus in Alzheimer's disease. Acta Neuropathol. 118, 497-504(2009).

5) Toorani, M.R.; Farhoosh, R.; Golmakani, M.; Sharif, A. Antioxidant activity and mechanism of action of sesamol in triacylglycerols and fatty acid methyl esters of sesame, olive, and canola oils. LWT - Food Sci Technol. 103, 271-278(2017).
6) Makedou, K.G.; Iliadis, S.; Gogou, M.; Kara, E.; Papageorgiou, G. Sesame oil: An ex vivo study of properties against oxidation of plasma low-density lipoproteins and total serum lipoproteins. Food Res Int. 58, 153-155(2017).

7) Lu, X.; Zhang, L.X.; Sun, Q.; Song, G.H.; Huang, J.N. Extraction, identification and structure-activity relationship of antioxidant peptides from sesame (Sesamum indicum L.) protein hydrolysate. Food Res. Int. 116, 707-716 (2019).

8) Pathak, N.; Verma, N.; Singh, A.; Bhat, K.V.; Lakhanpaul, S. Investigations on diverse sesame (S. indicum L.) germplasm and its wild allies reveal wide variation in antioxidant potential. Physiol. Mol. Biol. Pla. 26, 697-704 (2020).

9) Namiki, M. Nutraceutical functions of sesame: A review. Crit. Rev. Food Sci. Nutr. 47, 651-673(2007).

10) Hirona, K.; Chie, M.; Ayaka, S.; Nobuhiro, Z. Sesame extract attenuates the degradation of collagen and elastin fibers in the vascular walls of nicotine-administered mice. J. Oleo Sci. 68, 79-85 (2019).

11) Bae, J.J.; Yeon, S.J.; Park, W.J.; Hong, G.E.; Lee, C.H. Production of sesaminol and antioxidative activity of fermented sesame with Lactobacillus plantarum P8, Lactobacillus acidophilus ATCC 4356, Streptococcus thermophilus S10. Food Sci. Biotechnol. 25, 199-204 (2016).

12) Huang, J.N.; Song, G.H.; Zhang, L.X.; Sun, Q.; Lu, X. A novel conversion of sesamolin to sesaminol by acidic cation exchange resin. Eur. J. lipid Science Tech. 114, 842-848(2011).

13) Ohtsuki, T.; Akiyama, J.; Shimoyama, T.; Yazaki, Y.I.; Sadaharu, U.; Hirose, Y.; Mimura, A. Increased production of antioxidative sesaminol glucosides from sesame oil cake through fermentation by Bacillus circulans strain YUS-2. Biosci. Biotech. Bioch. 67, 2304-2306 (2003).

14) Osawa, T. Protective role of dietary polyphenols in oxidative stress. Mech. Ageing Dev. 111, 133-139 (1999).

15) Shin, S.Y.; Ahn, S.; Park, M.J.; Yoon, H.; Kim, M.J. Structure-activity relationships of polyphenols inhibiting lipopolysaccharide-induced NF-kB activation. $J$. Korean Soc. Appl. Bi. 55, 669-675 (2012).

16) Sarwar, M.W.; Riaz, A.; Dilshad, S.M.R.; Al-Qahtani, A.; Nawaz-Ul-Rehman, M.S.; Mubin, M. Structure activity relationship (SAR) and quantitative structure activity relationship (QSAR) studies showed plant flavonoids as potential inhibitors of dengue NS2B-NS3 protease. BMC Struct. Biol. 18, 6 (2018).

17) Dong, P.; Fu, X.; Wang, X.; Wang, W.M.; Cao, W.M.; Zhang, W.Y. Protective effects of sesaminol on BEAS2B cells impaired by cigarette smoke extract. Cell Biochem. Biophys. 71, 1207-1213(2015).

18) Cao, W.M.; Dai, M.J.; Wang, X.; Yuan, F.J.; Chen, F.X.; 
Zhang, W.Y. Protective effect of sesaminol from Sesamum indicum Linn. against oxidative damage in PC12 cells. Cell Biochem. Funct. 31, 560-565 (2013).

19) Huang, J.N.; Sun, Q.; Song, G.H.; Qi, S.N.; Chen, J.; Zhang, P.Y. Antioxidant and anti-isomerization effects of sesamol and resveratrol on high oleic acid peanut oil. LWT - Food Sci. Technol. 123, 1090077 (2020).

20) Peng, Z.; Xu, Y.Y.; Meng, Q.R.; Raza, H.; Zhao, X.Q.; Liu, B. Preparation of sesaminol from sesaminol triglucoside by $\beta$-glucosidase and cellulase hydrolysis. $J$. Am. Oil Chem. Soc. 93, 765-772 (2016).

21) Zhu, X.L.; Zhang, X.; Sun, Y.K.; Su, D.; Sun, Y.; Hu, B. Purification and fermentation in vitro of sesaminol triglucoside from sesame cake by human intestinal microbiota. J. Agri. Food Chem. 61, 1868-1877 (2013).

22) Jan, K.C.; Ku, K.L.; Chu, Y.H.; Hwang, L.S.; Ho, C.T. Intestinal distribution and excretion of sesaminol and its tetrahydrofuranoid metabolites in rats. J. Agri. Food Chem. 59, 3078-3086 (2011).

23) Ansaria, S.A.; Satarb, R. Recombinant $\beta$-galactosidasesPast, present and future: A mini review. J. Mol. Catal. $B$ 81, 1-6 (2012).

24) Jiokeng, S.L.; Dongmo, L.M.; Ymélé, E.; Nde, D.B.; Tonlé, I.K. Organoclay-film modified electrode for the detection of ultra-traces of $\mathrm{Hg}^{2+}$ ions: Approach of one factor at a time by an experimental design. Electrochim. Acta 316, 152-161 (2019).

25) Teng, H.; Lee, W.Y.; Choi, Y.H. Erratum to: Optimization of ultrasonic-assisted extraction of polyphenols, anthocyanins, and antioxidants from Raspberry $(R u$ bus coreanus Miq.) using response surface methodology. Food Anal. Method 8, 539 (2015).

26) Yeo, J.; Jeong, M.K.; Lee, J. Correlation of antioxidant content and absorbance changes of DPPH during lipid oxidation. Food Sci. Biotechnol. 21, 199-203 (2012).

27) Re, R.; Pellegrini, N.; Proteggente, A.; Pannala, A.; Yang, M.; Rice-Evans, C. Antioxidant activity applying an improved ABTS radical cation decolorization assay. Free Radic. Biol. Med. 26, 1231-1237 (1999).

28) Benzie, I.F.F.; Strain, J.J. The Ferric reducing ability of plasma (FRAP) as a measure of antioxidant power: The FRAP assay. Anal. Biochem. 239, 70-76 (1996).

29) Sarkar, A.; Jana, A.D.; Giri, N. Study of radical scavenging activities of a series of flavonoids through 3DQSAR analysis. Asian J. Chem. 30, 2394-2398 (2018).

30) Marot, C.; Baurin, N.; Mérour, J.Y. Imidazoline receptor ligands-molecular modeling and 3D-QSAR CoMFA. Molecular Modeling and Prediction of Bioactivity 349-350 (2000).
31) Souhila, B.T.; Redouane, T.; Safia, T.K. Receptor and ligand-based 3D-QSAR study on a series of nonsteroidal anti-inflammatory drugs. Med. Chem. Res. 22, 1529-1537 (2013).

32) Anusha, J.; Dandamudi, U.; Malathi, S.; Ram, R. Sesaminol diglucoside, a water-soluble lignan from sesame seeds induces brown fat thermogenesis in mice. Biochem. Biophys. Res. Commun. 507, 1-4 (2018).

33) Hou, J.G.; Xue, J.J.; Wang, C.Y.; Liu, L.; Zhang, D.L.; Wang, Z. Microbial transformation of ginsenoside Rg3 to ginsenoside $\mathrm{Rh}_{2}$ by Esteya vermicola CNU 120806 . World J. Microb. Biot. 28, 1807-1811(2012).

34) Liu, X.Q.; Jiang, Z.Q.; Ma, S.; Yan, Q.J.; Chen, Z.X. High-level production and characterization of a novel $\beta$-1,3-1,4-glucanase from Aspergillus awamori and its potential application in the brewing industry. Process Biochem. 92, 252-260 (2020).

35) Cheng, Y.S.; Ko, T.P.; Wu, T.H.; Ma, Y.; Huang, C.H.; Lai, H.L. Crystal structure and substrate-binding mode of cellulase 12A from Thermotoga maritima. Proteins 79, 1193-204(2011).

36) Nair, A.; Kuwahara, A.; Nagase, A.; Yamaguchi, H.; Yamazaki, T.; Hosoya, M. Purification, gene cloning, and biochemical characterization of a $\beta$-glucosidase capable of hydrolyzing sesaminol triglucoside from Paenibacillus sp. KB0549. Plos One 8, e60538(2013).

37) Park, A.H.; Oh, D.K. Galacto-oligosaccharide production using microbial $\beta$-galaclosidase: Current state and perspectives. Appl. Microbiol. Biot. 85, 1279-1286 (2010).

38) Phosrithong, N.; Ungwitayatorn, J. Ligand-based CoMFA and CoMSIA studies on chromone derivatives as radical scavengers. Bioorg. Chem. 49, 9-15(2013).

39) Paulina, U.; Bárbara, R.C.; Lucía, F.A. Detailed analysis of galactooligosaccharides synthesis with $\beta$-galactosidase from Aspergillus oryzae. J. Agric. Food Chem. 61, 1081-1087 (2013).

40） Bae, J.J.; Yeon, S.J.; Park, W.J. Production of sesaminol and antioxidative activity of fermented sesame with Lactobacillus plantarum P8, Lactobacillus acidophilus ATCC 4356, Streptococcus thermophilus S10. Food Sci. Biotechnol. 25, 199-204(2016).

CC BY 4.0 (Attribution 4.0 International). This license allows users to share and adapt an article, even commercially, as long as appropriate credit is given. That is, this license lets others copy, distribute, remix, and build upon the Article, even commercially, provided the original source and Authors are credited. 